\title{
Artificial Intelligence for successful Kflow
}

\author{
Eunika Mercier-Laurent \\ Magellan Research Center, Jean Moulin University, Lyon 3 \\ eunika.mercier-laurent@univ-lyon3.fr
}

\begin{abstract}
Since over twenty years now organizations have been tried various approaches of Knowledge Management beginning mostly with not always adequate tools. The feedback from AI experience shows that it helps elaborate a knowledge flow from building blocks of applications. These blocks providing various KM components should communicate to serve given organization and its stakeholders ensuring sustainable success of all participants. This paper discusses some selected experiences and performance of the flow using two main KM approaches. The influence of the knowledge flow on the capacity to innovate is also discussed. Finally, some perspectives on the impact of AI for improving Knowledge Management in organizations are given.
\end{abstract}

Keywords: Artificial Intelligence, Knowledge Management, Innovation, optimization, risk management, simulation, human-machine interfaces.

\section{Introduction}

The term of Knowledge Management has been introduced by management thinkers in the late 1980s as a new way of managing organizational talents and success. On the other side, since 1950s AI researchers have been working on knowledge acquisition, representation, modelling and processing. The AI community joined the KM movement through applications in various fields such as tutoring systems, medical or industrial diagnosis, optimization, scheduling, and training. The concept of Corporate Knowledge was introduced by AI practitioners in 1991 - they noticed that applications often share the same knowledge $[7,8,9]$ that should be organized to allow relevant access and serve for decision support. On our knowledge it was a first proposal of a company knowledge flow born from experience in applying AI approaches and techniques to face organizational challenges. The components of Corporate Knowledge follow the knowledge life cycle: Corporate Modelling, Corporate Memory, Corporate Navigation and Corporate Decision [7].

In the late 1990s the IT software vendors have begun pushing their products using the KM concept. They have been tried to introduce KM in companies through the basic tools such as excel, database or Notes (Lotus) supposed to be participative and shared by all employees. After some fails it was concluded that KM is not accepted by addressed people, without understanding the real causes of rejection. Most of them are related to human nature and culture: ability and willingness to share knowledge 
and experience, ability to listen and learn from others experience, motivation for collaborative work or incentives and recognition system. In most of cases to the employees needs stopped to fill databases because of the lack of realistic goals, related to their needs.

From IT side the above mentioned tools were not designed to facilitate knowledge acquisition; interfaces of acquisition and search were not users friendly and it was not easy to find quickly a relevant answer. All these tools were based on data processing instead of on knowledge processing methods.

Organizational website [7], Intranet, Workflow and Electronic Document Management have been later considered as KM tools. The barriers for using these tools were similar.

Web 2.0 brought more services such as forum, e-commerce, e-learning and social networks. However all these services are still not conceived with "knowledge" approach. They focus on content and not on needs. By consequence they still do not offer "in one click" finding of only relevant information and knowledge. Software companies offering free search engines add a flow of advertisement before the results and it is time consuming to find relevant information in the "hay stack". User is considered as source of data and targeted for pushing any kind of advertisements. All visitors are seen as potential buyers and these companies are more interested in credit card number then in their real needs. The real knowledge about users is not important, .log, cookies and analytics generate a lot of useless data.

Social networks, that could be very powerful for KM, are mainly used for advertisement of personal activity in various interest groups. Advertisements again are inserted everywhere. Not easy to know what is really relevant, because it is a lack of consistency checking between various postings (AI again).

Enterprise Social Networks (ESN) are now considered by many as a trigger for organizational knowledge management [5]. The main problem with social networks is an attitude of using them - their users post information about themselves and do not "listen" enough to the others. In companies they may provide information on capacities and experience of the employees, their connections and projects they participate. Equipped with an intelligent search engine for finding the right skill, competency, experience or document they could enhance the traditional software.

Wiki that has been introduced in late 1990s and is still the best way to initiate a KM process is little used. The excellent tools, such as wetpaint, very friendly and suited also for e-teaching, has changed its strategy and is devoted now to news about "celebrities". Google provides similar facilities, such as G+ and Google docs but does not offer a private collaborative e-space for storing all documents related to a given course or project, information about participants skills and experiences, discussions and applications in the same secure and easy to access, update and follow by members place. 
The traditional IT way of thinking and programming leaded to accumulation of huge amount of data. Big Data and mining "knowledge" from them using mainly analytics is one of the last trends [17, 24]. Many imagine delivering new services from Big Data and in particular in the context of Smart Cities [18, 25].

In this context client is considered as a source of data and targeted, while Amidon [15] recommend involving client/citizen into the Knowledge Management dynamics and into the innovation process (innovating with client).

By opposite, the knowledge-bases applications corresponding to real needs and developed with related professionals such as collaborative experience for diagnosis, tutor systems, intelligent electronic commerce, configuration systems, process control, human resources management and many others have been successful. However in the most cases the knowledge flow was limited to one or two communicating applications such as diagnostic system, also used for training, customer support providing feedback to development department, configuration system and e-business, ecodesign and some others. The main reason was that these applications were developed on middle-management level and their initiators and users were happy with such solutions enhancing their work efficiency. Most of them did not try to promote these applications to the strategic level and extend to other users.

The long experience of AI practitioners is little visible and not enough shared with other professionals, because of different motivations of researches and business people. Companies professionals have no time to publish for research conferences and journals and research people consider industrial applications not enough scientific. Yet, the industrial problems challenging for research, may sometimes seem too difficult for researchers. In fact the real world problems require often a hybrid solution using a combination of several techniques while researchers focus mainly on one discipline. Multidisciplinary research is encouraged but weakly considered by academic evaluation systems.

This situation may evolve with the new trend of "stimulating industrial renewal" and with AI current trends of computational machine learning applied to cities, marketing and energy optimization [34].

The first part of this paper presents a brief state of the art focus on the connection between $\mathrm{AI}$ and $\mathrm{KM}$, second mentions some examples of AI powering an organizational Knowledge Flow, third put an emphasis on the importance of feedback integration and experience sharing and final discussion set some perspectives for enhancing KM and innovation capacity by AI approaches and techniques.

\section{State of the art}

Despite numerous experimentations only few organizations practice the systematic Knowledge Management covering all company functions and all stakeholders' needs including clients. Currently two main trends are user's oriented and management 
oriented (few). While management oriented approach focuses mainly on tangible and a little on intangible values, as for example marketing, business development, human resources [3] and Business Intelligence, the new trends such as Sustainability, Corporate Social Responsibility, management of intangibles, social innovation, "greening", eco-design, eco-innovation, open innovation and wellbeing offer new perspectives on enhancement of current KM experimentations [3, 9, 19, 20, 21, 22, 23, 35].

The KM cycles are similar that those of AI. After tools oriented initial enthusiasm, without considering the AI experience, it was said that $\mathrm{KM}$ is not working, without understanding and analyzing the real causes of fails. Now KM is practicing in companies and organization, but few communicate on "Knowledge Management". They rather focus on knowledge-based innovation [36].

After initial enthusiasm and declining, Artificial Intelligence is now embedded and emerges through robots, serious games, ambient intelligence, IoT, augmented human, transhumanism and others. The trends such as Big Data and analytics, multimedia search or needs for optimizations livens up the renewed "old" techniques such as artificial neural networks, genetic and evolutionary algorithms $[17,24,25,38]$ became more effective thanks to increasing performances of computers.

In companies KM mostly focus on just one component of the flow because it is easy to demonstrate that it works. In most cases it remains more difficult to demonstrate short-term benefits from them [13] without regular evaluation of progress [15, 9]. Decision support systems are more difficult to built but the benefits are easiest to assess.

Some examples of connecting several applications such as managing best practice with feedback on products or service improvement or reusing the acquired experience on field in maintenance and for training can also be found $[8,38]$.

Corporate Intranet is in some cases presented as a backbone of Knowledge Management...mainly without AI.

While open social networks offer a lot of not qualified information, the enterprise social networks providing targeted information and knowledge have a special influence on easy initiating the KM process. Such a network when correctly managed provides more information on company intellectual capital, projects, help in finding person who knows, initiate collaborative projects by connecting right people. While it is easy to introduce them, the sustainable dynamics requires the continuous implication of facilitator to stimulate exchanges and manage the system [5]. AI may enhance this initial dynamics by providing capitalization facilities, instant access to knowledge through knowledge model navigation, problem solving, relevant advice, simulation, training and cross fertilization. The sine qua non condition is the systematic knowledge modeling and using AI techniques. 
The trends such as Smart, Knowledge, Innovative or Wise City are the opportunity for introducing the both: Knowledge Management supported by AI approaches and techniques. Publications such as [18, 26, 27, 32] and certainly others give some ideas on how KM may enhance the intelligence of city actors and collaborative innovation. $\mathrm{KM}$ empowered by AI is certainly practiced by few city actors, companies and universities, but not necessary known by the city authorities. The communication between actors through the city website or collaborative actions may give interesting results [11].

While theoretical literature on overall organizational knowledge flow abound, there are only few companies having developed an overall organized and optimised knowledge flow serving firm and stakeholders' needs $[8,9]$.

Artificial intelligence has been brought a huge contribution to the excellence and effectiveness of $\mathrm{KM}$ in term of thinking and problem solving methods, but also through knowledge acquisition, modeling and processing [9], decision support systems, intelligent tutors, planning, scheduling and optimization systems [10, 39, 40].

Industrial risks, risks increasing with globalization and new risks such as lost of long-term knowledge [28, 29], lost of cognitive capacity due to replacing human by autonomous intelligent devices, cyber-criminality and others [30] cannot be faced without systematic Knowledge Management.

Today AI is powering all functions and will play (we hope) more important role in IT. AI is in the search engines, in training systems (serious games, e-learning with virtual tutor) in risk management, process control, manufacturing, scheduling, procurement and many others. The recent conferences such as APIA [6] PAIS [33] and AFRICON 2015 [32], among others demonstrated growing interest for KM powered by AI.

Today Internet with all services is polluted and vulnerable to attacks from hackers. More AI is expected in Future Internet [14] as well as for knowledge modeling, knowledge navigation, various processing techniques (back to Corporate Knowledge) and before all "knowledge thinking" in teaching and designing of services and security systems. Computer security is increasingly important in the context of big data, cloud, connected objects, M2M communication and autonomous devices. KM with $\mathrm{AI}$ is already tried to discover incitement to terrorism by social networks.

Knowledge Management follows similar evolution as AI - early enthusiasm, deception from doing things wrong and weak renaissance with web 2.0. We hope that massive digitalization and deception from analytics as well as sustainability will bring more interest for KM powered by AI.

Scientific experiences are shared in some KM conferences such as EGC in France [49] and ICICKM [50] and others in the world. We also expect that "knowledge cultivators" in companies and organizations will share their experience to inspire the others and provide them some tips for success. Objective is however to see applying KM 
to the cities, regions, countries and in the world as a whole by applying the principle of knowledge holonomy introduced by Amidon [15].

\section{AI contribution to $\mathrm{KM}$}

On our knowledge the first convergence between AI and KM was the Corporate Knowledge architecture proposed in 1991 [8]. AI researchers and practitioners introduced and experienced several methods for knowledge modeling, acquisition and processing using various AI techniques adapted to knowledge capitalization for problems solving. Tools as Open KADS [51] for collaborative knowledge modeling including objects, ontologies and a library of generic reasoning models were conceived for specific needs of process control.

Knowledge capitalization has been made in cause-to-effect graphs, expert systems or case-based reasoning tools for process control, diagnosis or other problems solving, design or training. Since 1976 the principal machine learning algorithms such as ID3 and AQ to learn from examples have been known and experimented [42, 43].

Natural language programming for direct access to knowledge have been proposed from the 1970 and improved through experiments. Techniques such as constraint programming, multisystem agents, artificial neural networks, genetic and evolutionary algorithms, natural language processing have been successfully applied for scheduling, manufacturing, planning, robots programming and other problem solving in many fields. The Figure 1 shows the currently available AI techniques. All are useful for Knowledge Management.

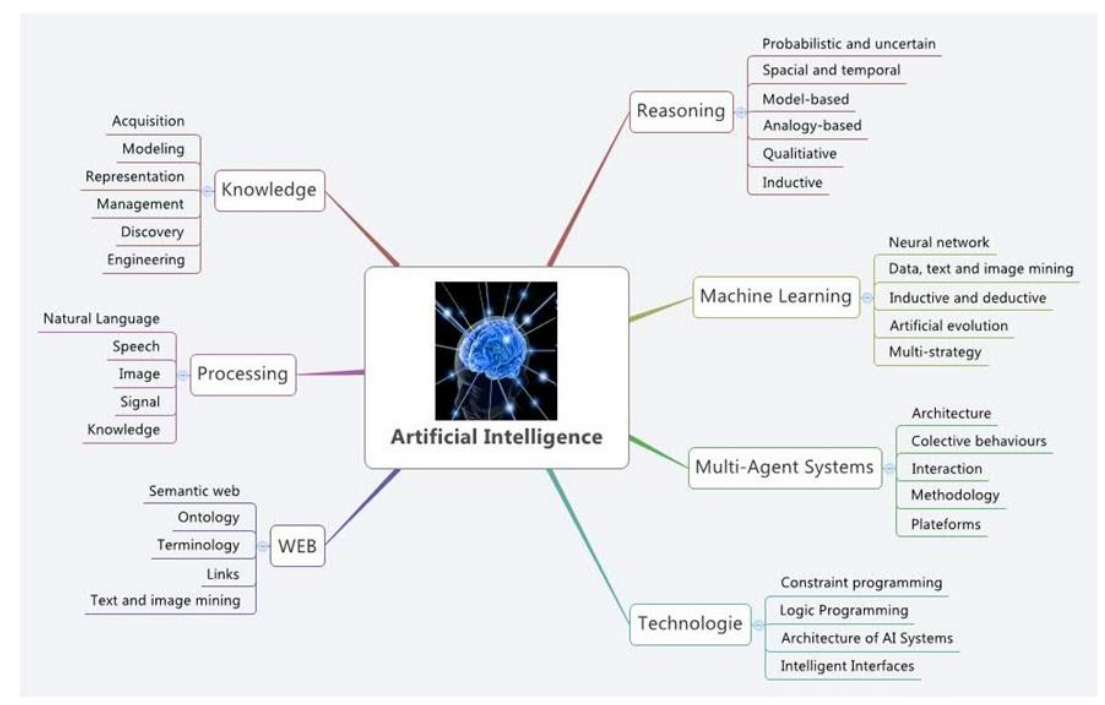

Figure 1 - Mapping of AI techniques and disciplines [38]. 
The feedback from experience demonstrated that solving complex "real-life" problems requires a hybrid architecture combining several techniques. For example: management of Intellectual Capital may use traditional data base, graphical display system to know what we have and expert or analogy engine to find what we need and update what we have. Constraint propagation may be added if we want to plan the use of talents for various short-term and long-term projects [3].

An "e-coach" for eco-design may include an expert systems for the right choice of environmental rules that apply in a given field (textile, mechanics, electronics..), but also case-based reasoning supporting a product line and constraint propagation system for optimized cut.

Process control exploring the signals from sensors may use an expert system, depending on the nature of knowledge.

Searching details in the flow of images may be supported by a hybrid system connecting multi-agent systems, neural networks in a basic system.

To summarize we can say that the first contribution is an "AI way of thinking" facilitating in-depth problem understanding, taking also into consideration all contextual knowledge necessary for adequate solving of a given problem. This way of thinking applied to Knowledge Management helps understanding what knowledge is important, where it is, who need it to act. Internal and external knowledge of stakeholders, in computers and in clouds is considered as well.

The second contribution is a large spectrum of knowledge models including ontologies, reasoning methods and models, algorithms, non-standard logics, knowledge discovery techniques from databases, text and images, machine learning and computational intelligence techniques as well [52].

Today trend to solve every kind of problems with computational intelligence is good for data flow but not for knowledge flow.

The third contribution is a great worldwide experience - applications in all fields to inspire the innovative solutions. A knowledge base of these experiences offering relevant access to experiences will be very useful for inspiration and for learning, but it is still to build. The last trend of industrial renewal [53] provides a playground for reusing existing knowledge and experience in AI.

AI helps defining a goal, strategy and tactics for top-down approach and building incrementally the whole knowledge flow from connected building Kblocks when using bottom-up approach. Demonstrating that it works and brings benefits to all participants is possible with the adequate metrics such as those described in $[9,15]$.

Smart Knowledge flow has to support all activities of given organization, including also stakeholders such as partners, distributors and clients. 


\subsection{Knowledge Flow}

The main task of knowledge management is to gather and provide relevant knowledge to all participants. Knowledge flow can be defined as follow:

"Creation, collection, processing and sharing of information and knowledge in an organized and optimized way, taking into consideration the different activities of the extended organization as well as needs and individual and collective motivations of all participants" $[8,9]$.

Figure 2 shows an example of such a flow.

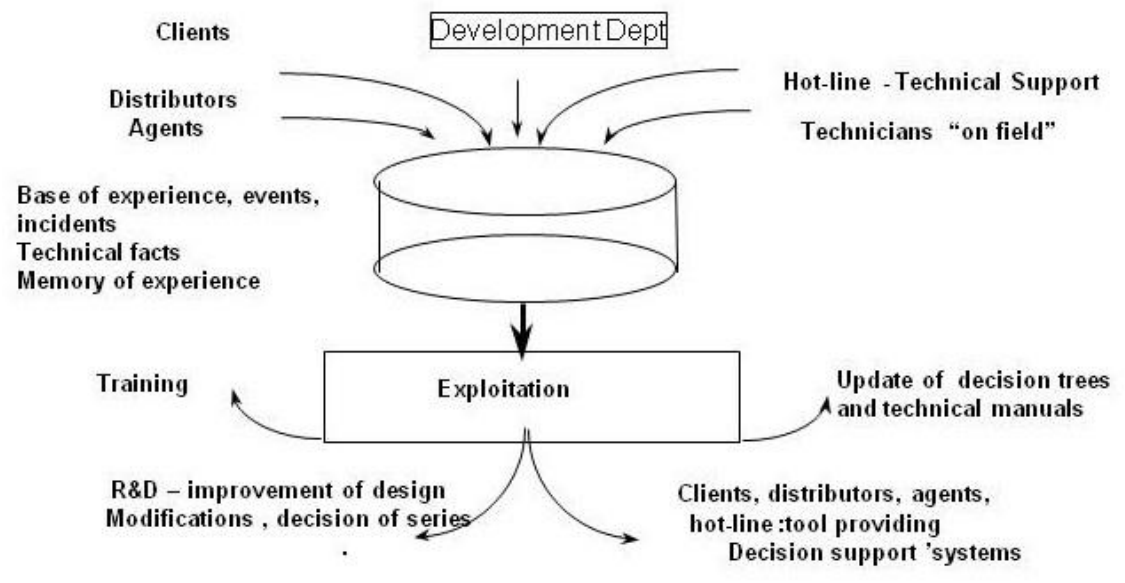

Figure 2 Example of knowledge flow

Knowledge flow may be composed of communicating applications covering the needs of extended organization. The architecture of the flow should be defined as building Kblocs (as LegoTM) allow adding new components, sharing the previous stored knowledge or introducing new elements to share by participants. In this context, computers, smartphones and other connected devices have to play a role of intelligent assistant of humans. Equipped with embedded "intelligence", they have to be used for the tasks they perform better than human do. They learn from their users activities to improve their performances. It is a condition of usefulness of KM for the participants, basic for their active participation.

The optimization of the Kflow cannot be made without a global view and in-depth understanding of all stakeholders' needs and activities. What, who, why, for whom are the fundamental questions to ask. The current state of exchange and desired ones should be elaborated with the future users. The related knowledge will then be mod- 
eled (conceptual modeling) allowing further update and reusing. It is not necessary to gather all knowledge first, as some are doing, just parts for immediate exploring. Such a way of building a knowledge flow leads to "green software" and contribute to sliming the data centers. Understanding first takes time, but it is vital for architecturing the system able to really help people performing better their work.

\subsection{Organizing and optimizing the sources of knowledge}

Organizing is about a KM approach suitable to a given situation and using right tools. Knowledge modeling following the principles of modularity, genericity and reusability [8, 9] facilitates the optimization of the Kflow. The Corporate Knowledge model and knowledge bank can be than easily updated when appropriately defined and designed. The libraries of knowledge models and reasoning will facilitate smart seamless extension. Appling the basic algorithms of multi-strategy machine learning $[42,43]$ helps in transforming specific to general that maybe useful for future reuse (ontologies, reasoning models, etc).

The knowledge acquisition systems benefit from long experience of expert systems in term of collaborative knowledge modeling using graphical interface. Now the multimodal interfaces are replacing traditional keyboard - smart phones are in advance in this field. However the way of programming should evolve to fit to human reasoning instead of following trees. Typical example is on board computer in some cars.

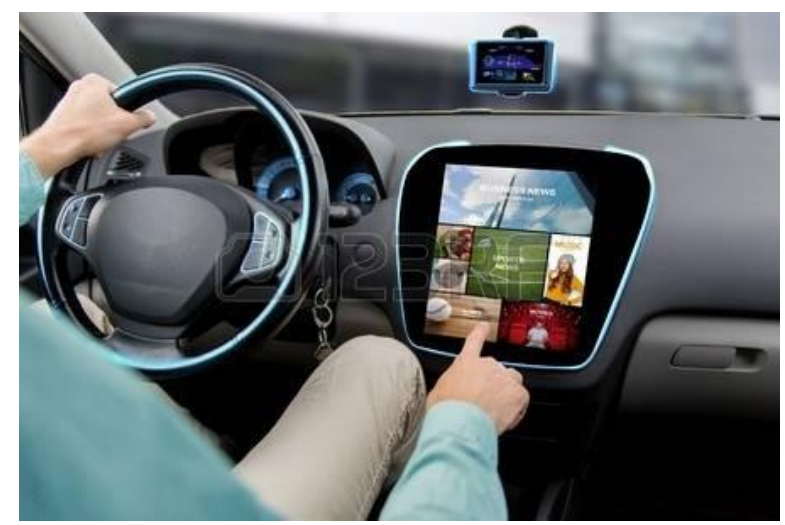

Figure 3 Driving and clicking may lead to accident (source http://www.123rf.com)

Even when voice interface is provided the driver has to follow the tree logic to ask questions. For example if I want to go to a new place I have to choose first the country, then city and street and number, while it could be said in the same sentence.

Some smart phone apps provide such a direct access. Car designers may take inspiration from this kind of applications.

Electronic commerce and some platforms for matching offer and demand are programmed using the same logic, what make the system inefficient for the user. 
Knowledge discovery techniques such as induction, genetic algorithms, neural networks and natural language processing helps in finding "hidden" knowledge in huge amount of data, texts and images. Nearest neighbor algorithm of case-based reasoning may be also used for automatic cleaning data before applying data mining techniques. All these techniques are available, but the main barrier to machine efficiency is the advertisement based business model pushing the paid advertisements first. Often it is a long list to check and the provided answers are not relevant.

\subsection{Facilitating Knowledge creation}

As results of years of research and experimentation in machine learning, natural language, signal and image processing techniques for knowledge discovery are henceforth available and tested on many cases. Multimodal knowledge acquisition (voice, gesture, emotion) powered by machine learning and data mining, text mining and image mining algorithms is complementary to human knowledge creation and of a large scope. Automatically acquired knowledge can be validated by experts if necessary. An example of voice knowledge acquisition is shown in Figure 4.

Connected computers embedded with machine learning algorithms can learn from social networks, texts, forum exchanges and other potential sources of knowledge. Data mining is now applied in many fields not only in marketing but also in health, forecasting, banking and others. 


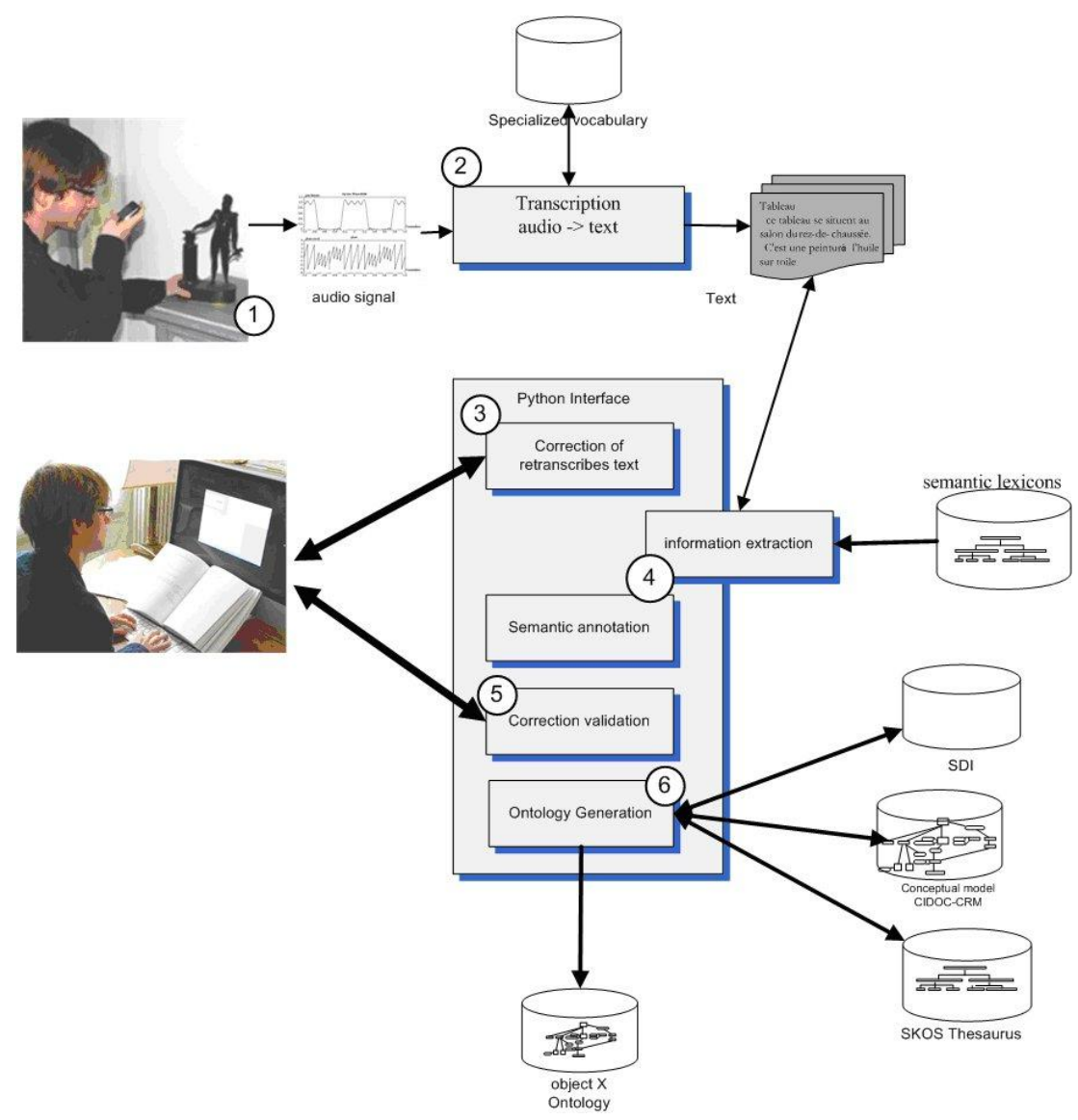

Figure 4 Example of automated knowledge acquisition from voice description of historical objects [4].

\subsection{Smart finding and share}

Equipped with machine learning algorithms computer is able to learn from its user and provide to him/her just the information and knowledge he/she is interested and/or required for performing better [9]. On our knowledge this very useful capacity is not implemented yet. Compared to current collecting of "information" about users' navigation from clicks this approach is radically different because it explores knowledge, not non-qualified data. The use of the last generates a lot of "intellectual" pollution for users. They are frustrated because they cannot easily find what they are looking for and they lose time. Visual pollution by pop-up advertisements makes the search more difficult.

The multilingualism in search engine should also be improved. My computer knows what language I use, but software companies often forgot that the user may 
speak several languages and search information using them. Search engines use only one - those of your country. Sometimes the automatic recognition of the user language changes your "language" parameter and the next results are automatically displayed in the previously used language, even if the question is asked in another language.

The pre-selected information and knowledge by computer machine learning algorithms should be filtered and its consistency verified, crossing several sources, before delivering to the users. Such logic can enhance human sharing by providing accurate elements of knowledge, access to decision support systems, tutoring systems, simulators. The sharing process will work if participants are motivated to do that and if they get in exchange what is useful and helps them to perform better. The knowledge models facilitate and accelerate relevant search limited to a given area covered by explored knowledge model.

\subsection{Collective knowledge and experience}

One of the main components of Kflow is collective knowledge and experience. Databases, forums and social networks contain some elements of knowledge, but they are not efficient in finding. The long experience of AI in building knowledge-based systems facilitates the choice of right method and adequate tools. The most important is to understand what should be preserved, who will use it and for doing what. In some fields such as nuclear waste, the related knowledge should be available for two centuries.

The nature of knowledge to collect and proceed will guide the choice of models and reasoning methods or others computational intelligence techniques that are effective in a given case. The main $\mathrm{AI}$ techniques used for capitalization are expert systems and case-based reasoning, but multi-agent systems can also be useful. The knowledge of stakeholders such as distributors, partners and clients may be strategic for products improvement and for future development as shown in Figure 5.

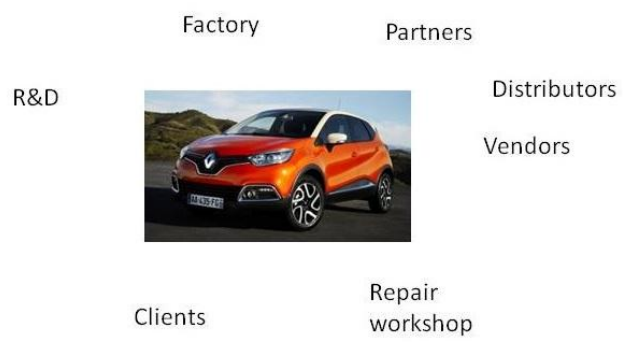

Figure 5 Example of Extended Business Networks in automotive industry.

Most common example of collective knowledge is a base of experience in maintenance, technical and medical diagnosis. Such a collective knowledge is necessary for 
supporting on field technicians, especially in small companies, remote medical diagnosis in case of emergency or rare disease, for manipulation of dangerous materials and for complex problem solving requiring knowledge from several disciplines or simply for inspiration.

Databases, forums and social networks are not effective for knowledge capitalization, because often it is not evident to find quickly the right information or knowledge. The researchers working on deep learning promise the spectacular results [47].

\subsection{Decision Support (diagnosis, process control, optimization...)}

The collected knowledge will serve to build decision support systems. There were among the first AI applications. Today we can find all kind of systems for diagnosis including organizational to find what is wrong, in medicine, chemistry, mechanics, nuclear plants and many others. Application to industrial process control using M2M transfer, optimization or manufacturing help human to make a right choice. Currently used decision systems are fully integrated to companies' information systems or available as mobile applications.

Simulation systems in many fields support training as for ex pilots, medical, mechanics, chemical, pharmaceutical.

In industry simulation is particularly helpful in eco-design and for entire innovation process. In eco-design it helps evaluating the various impacts before doing, choosing the right materials for production and recycling [9].

Since years AI help optimizing processes, planning, scheduling and manufacturing. In function of problem to solve the constraint programming or computational intelligence tools may be used.

\subsection{Training and education}

$3 \mathrm{~W}^{1}$ learning and training is now offered through e-learning and m-learning platforms. The most of them do not include the interaction with the learner, immediate evaluation of acquired knowledge and the art of using it in real situation.

The cultural progress of games allows now their use for training and learning. Behind there are a strategy, decision taking and multi-agent systems. Various approaches can be applied in function of situation and knowledge that should be acquired. Multimedia [2] and transmedia learning systems powered by AI (MSA, smart tutoring, smart assessment) make learning a pleasure. Playing a game is much more effective than explaining how to act. Natural language dialogue and gesture facilitates exchanges between player and machine.

AI helps in learn from the trainee, how he/she progresses, what kind of exercises are the best suited for effective training.

The power of computers allow combine the various media as music, video how to play, how to cultivate specific plants, preserve natural ecosystems [41].

\footnotetext{
${ }^{1}$ What you want, when you want, where you want
} 
The paper "From Knowledge to Sign Management- a co-design methodology for Biodiversity and Music enhancement" [54] of this collection describes in details such a system.

It is possible to find a game to learn how to preserve water when practicing various sports [45], to practice ecotourism or simply learn a new profession [46].

Training by playing allows also learning various strategies.

Tutoring systems with embedded AI have been experimented since years. AI techniques and interaction with e-professor or e-expert allow monitoring learner in his/her learning process.

\subsection{Help to innovate}

AI may support the whole innovation process - creativity, simulation before doing, reusing the best practices, smart design, taking into consideration the impact on environment of a given product from manufacturing to recycling.

The human creativity can be amplified by electronic generator of ideas presented in Figure 6.

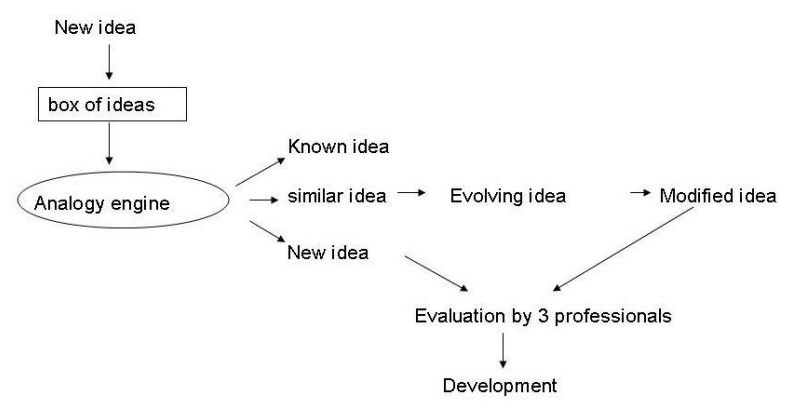

Figure 6 Generator of ideas using analogy engine [9].

Knowledge from outside may improve the internal creativity. Usually in the firms only $\mathrm{R} \& \mathrm{D}$ department is in charge of innovation. However stakeholders have also knowledge and experience that can be useful and in particular their ideas may lead to improvement of existing offer and to disruptive innovation. Involving client into a company innovation process is not yet understood as opportunity and advantage. Few IT firms practice Users'Clubs - they invite users to share experiences and applications. Such meetings are always a play a role of pollinisators and learning is mainly human but the feedback helps improving their products and answers better the clients' needs. In the case of Open Innovation clients are supposed to participate, but it is not always a case.

Difficult to imagine Smart, Green or Wise City without AI. City is supposed to offer public services to citizens and firms [1]. To offer relevant services the needs should be known. Citizens have also knowledge and experience to share. While today 
Smart City is mainly connected city, it is a lot of optimization to provide - in transportation, intelligent use of energy, water and other resource, finding talents, right service in my area and many others.

Modern University [11] has to provide knowledge to students but should also manage resources, attract students, innovate in programs and gain or maintain a leader position. AI has potential to support all these activities, but the vital principle to consider is that AI should transform computers into intelligent assistants of humans and not replace them.

Silver generation is mainly considered as a market, but some may be also skilled with long experience and brilliant brains. Smart city knowledge flow has to connect all actors.

The citizens are the players of social innovation. Some groups on social networks share experiments, but we still do not have a world base of experimentations [48].

Open Innovation Strategy and Policy Group [47] launched quadruple helix method connecting all kind of users; they prototyped during an EU funded projects. Some of these projects continue through Enoll initiative ${ }^{2}$.

\subsection{IOT}

Sensors and connected objects are now everywhere - in buildings, autonomous cars, drones, robots... Industrial renewal focus on massive introduction of IT into industry, but this revolution should be more AI-based. Today mainly data exchange is used; knowledge exchange between them is the next step. AI allows computers to gain a deeper "understanding" of images and their context "seen by IoT, to "hear," gathering sonic information about the user's environment, detect critical situation (earthquake, accidents, water leak..), recognize offender or terrorist.

Nevertheless IOT could be conceived using knowledge approach from the beginning [55].

\subsection{Risks Management}

The globalization and web development introduced new risks that have to be managed, see Figure 6.

\footnotetext{
${ }^{2}$ http://www.openlivinglabs.eu/
} 


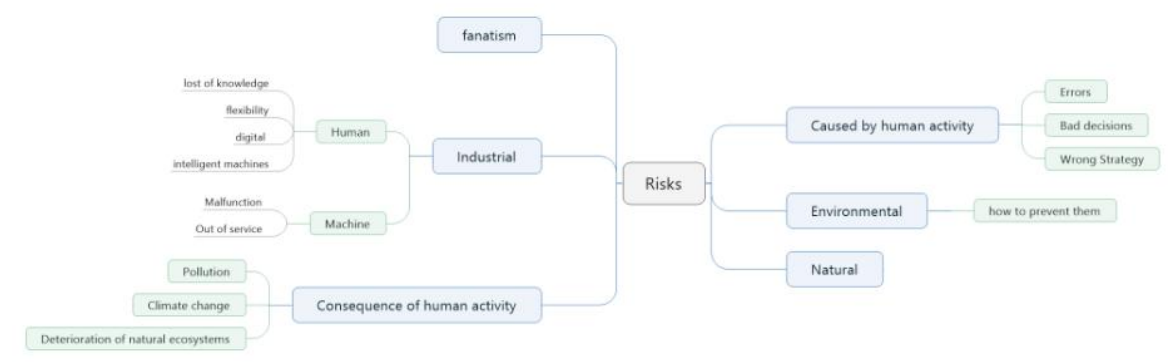

Figure 6. Known and new risks to be managed.

Among the new risks we can mention a loss of knowledge due to two main factors: retirement of experts and cognitive impact of technology. Knowledge transfer from expert to computers is often underestimated in terms of time necessary to do it and tools. Strong reliability on technology prevent from training the brain.

Main risks related to knowledge flow are cyber, but companies are exposed to all of them. AI way of thinking help preventing them when it is possible, by connecting all related, often multidisciplinary knowledge, reusing feedback from past experience and simulation.

\section{$4 \quad$ Feedback from experiences}

Since over 30 years know AI methods and techniques have been tried, but the feedback from this experience is few considered, because the society is still split into boxes and each "community" act in its own box. Humans prefer experimenting by themselves than reusing the others experience. The emerging multidisciplinarity principle may improve this situation, but it takes time to change people.

The recent trends such as ambient life, robots, connected objects, renewed and amplified the interest for AI [17, 25]. Robots integrate the best of AI symbolic and computational, serious games use multisystem agents, scenarios, strategies.

The IT people awakes about AI possibilities, AI is now embedded in some IT tools, but the main barrier is the way of thinking: the IT people think "data and information", while AI require thinking "knowledge".

The recent spreading of computational intelligence techniques and tries to apply them to any kind of problem solving could not make us forgot the others AI techniques. The main principle is to know them and learn how to use and combine them in given contexts for the optimal and effective problem solving.

\section{Discussion and perspectives}

AI added value for supporting Knowledge Management has been proven and we expect the spreading of the growing trend for multisciplinarity in many fields will 
enhance the use of AI methods and techniques to empower KM in organisations (university, political, NGO...) and companies. The important challenges to face are in industrial renewal, energy and water optimization, sustainability, planet protection, greening, smart design, growing cities but also medicine, natural disasters, criminality and cybercriminality.

It will be interesting to have a global base of experiences in applying AI to real life problem solving.

While AI is often hidden (inside) we also hope that it will be emerged to demonstrate that all over 50 years of research and practice is really useful. We hope that AI will enter to many fashionable domains such as Smart city, eco-innovation, global greening, connected objects, future internet and others. We also expect more students' interest in real life problem solving and better synergy with industrial and other companies' activities.

The rise of risks and planet protection introduced new challenges. Globalization made the relations company-customer-partners more intensive and requires the systematic Knowledge Management. The EU programs produced a lot of knowledge but the EU is not practicing KM. There is the same for growing cities, regions. Managing knowledge should become holistic and a duty of citizens, politicians, organizations, companies and NGOs. AI has to provide an intelligent support for human facing all these challenges.

\section{References:}

1. Adrian W., Ligeza A., Nalepa G.: Description Logic Reasoning in an Ontology-Based System for Citizen Safety in Urban Environment, AI4KM, ECAI 2012, Montpellier, France

2. Conruyt N. E-co-innovation for making e-services. Living Labs as a human-centered digital ecosystems for education with ICT, DEST 2013, Palo Alto, US.

3. Mercier-Laurent E.: Trends and Challenges for Intellectual Capital, chapter in the book Intellectual Capital in Organizations. Non-financial Reports and Accounts, Eds Edvinsson L., Ordonez P. , Routledge, 2014

4. du Château S., Boulanger D., Mercier-Laurent E. : Managing Domain Knowledge: Application to Cultural Patrimony, Knowledge Management Research \& Practice (2012) 10, 312-325, Palgrave Journals

5. Le Moing B. : Schneider-Electric : La gestion des connaissances au cœur du programme d'entreprise, Qualitique, $\mathrm{N}^{\circ}$ 256, Novembre 2014, pp.

6. Lourdeaux D. : Applications Pratiques de l'Intelligence Artificielle, Plateforme Intelligence Artificielle, 2015, Rennes

7. Mercier-Laurent E.: Global Knowledge Management beginning from website - How to organize the Flow of Knowledge in an International Company - theories and practice ISMICK 97, Compiegne

8. Mercier-Laurent E. : Rôle de l'ordinateur dans le processus global de l'innovation à partir des connaissances, Habilitation pour Diriger des Recherches, Université Jean Moulin Lyon 3, 2007

9. Mercier-Laurent E.: Innovation Ecosystems, Wiley, 2011

10. Mercier-Laurent E. Boulanger D. (Eds), Artificial Intelligence for Knowledge Management, Revised Selected Papers, Springer IFIP AICT 422, 2014 
11. Owoc M.L., Marciniak K/ Knowledge Management as Foundation of Smart University, Fedscis, 2013, Krakow, Poland

12. PAIS 2014 proceedings, ECAI 2014, Prague, http://www.ecai2014.org/pais/

13. Rouleaux-Dugage M.: Management de la connaissance et gestion des risques technologiques au sein du groupe AREVA, IMdR, 12 juin, 2014, Sceaux

14. Future Internet https://www.fi-ppp.eu/

15. Amidon D. The Innovation Strategy for the Knowledge Economy, Butterworth Heineman, 1997

16. Kitamura S. Et al ., "Modified multiobjective particle swarm optimization method and its application to energy management system for factories", Electrical Engineering in Japan, vol. 156 , no. 4, pp. 33-42, 2006.

17. IJCAI 2015 http://ijcai-15.org/

18. Smart city \& big data http://www.mec.edu.om/conf2016/index.html

19. Zhang F., Maud R., Allais R., Zwolinski P., Reyes-Carrillo T., Roucoules L., MercierLaurent E. and Buclet N. (2013) Toward an systemic navigation framework to integrate sustainable development into the company, Journal of Cleaner Production Volume 54, p. 199-214, 1 September 2013.

20. Sustainable Development http://ec.europa.eu/environment/eussd/

21. McWilliams A., Siegel D., Corporate social responsibility: A theory of the firm perspective. Academy of Management Review, Vol. 26, p.117-127, 2001.

22. Mercier-Laurent E.: The Innovation Biosphere - Planet and Brains in Digital Era, Wiley 2015

23. Metalsa Model www.metalsa.com.mx/modelo_metalsa.html.

24. Fedscis 2016 https://annals-csis.org/volumes

25. IJCAI 2016 http://www.ijcai.org/Proceedings/2016

26. Marciniak K.: Concept of the urban knowledge. A case of Poland, KAM/Fedcsis 2016, Gdansk, Poland September 11, 2016

27. Adrian W. T., Ligeza A., Nalepa G., Kaczor K : Distributed and Collaborative Knowledge Management using an Ontology-based System, in Artificial Intelligence for Knowledge Management, Revised Selected Papers, Eds Mercier-Laurent E., Boulanger D., Springer IFIP AICT 422, p.112-131, 2014.

28. Dourgnon A., Roche C., Mercier-Laurent E.: How to value and transmit nuclear industry long term Knowledge, ICEIS 2005

29. Bienvenu H.: La gestion des connaissances au sein de l'Agence nationale pour la gestion des déchets radioactifs (ANDRA), Qualitique $\mathrm{N}^{\circ} 256$, Novembre 2014

30. Mercier-Laurent E. Risks \& KM, KAM 2016

31. Engineering Applications of Artificial Intelligence, Elsevier http://www.journals.elsevier.com/engineering-applications-of-artificial-intelligence/

32. Africon 2015, IEEE Conference, Addis Ababa, Ethiopia, September 14-17, 2015

33. PAIS http://www.ecai2014.org/pais/

34. Kayakutlu G., Mercier-Laurent E.: Intelligence in Energy, Wiley 2016

35. Open Innovation Yearbook 2015 https://ec.europa.eu/digital-single-market/en/news/openinnovation-20-yearbook-2015

36. ST Microelectronics http://www.st.com

37. Auriol E.: Intégration d'approches symboliques pour le raisonnement à partir d'exemples, PhD thesis, Paris IX, 1995

38. $4^{\text {th }}$ Workshop Artificial Intelligence for Knowledge Management, IJCAI 16, New York, 2016. 
39. Boulanger D., Owoc M.L, Mercier-Laurent E.: $2^{\text {nd }}$ Artificial Intelligence for Knowledge Management, IFIP AICT 469, Springer, 2015

40. Ismick, http://www.utc.fr/\%7Ebarthes/ISMICK05.html

41. Conruyt N., Sébastien V., Sébastien O., Grosser D., Sébastien D. From KnowledgeTransmission to Sign Sharing: Semiotic Web as a New Paradigm for Teaching and Learning in the Future Internet, in Artificial Intelligence for Knowledge Management, Revised Selected Papers, Eds Mercier-Laurent E., Boulanger D., Springer IFIP AICT 422, p.170-188

42. Michalski R.S., Carbonnell T.J., Mitchell T.M.: Machine Learning: An Artificial Intelligence Approach, Tioga Publishing, Palo Alto, 1983

43. Michalski R.S. (Eds) Machine Learning: A Multistrategy Approach, Volume IV, Morgan Kaufmann Publishers, 1994

44. IRA http://www.ira.eu/ira_elearning.php

45. http://dufloconalavague.org

46. This is European Social Innovation, European Union, 2010, ISBN: 978927970751

http://ec.europa.eu/enterprise/flipbook/social_innovation/files/social_innov.pdf

47. Goodfellow I, Bengio Y., Courville A.: Deep learning, www.deeplearningbook.org, 2016

48. Curley, M., Salmelin B.: Open Innovation 2.0: A New Paradigm, EU Open Innovation Strategy and Policy Group (OISPG), 2013, available at bit.ly/OI2WhitePaper

49. EGC http://www.egc.asso.fr/

50. ICICKM

https://www.seas.gwu.edu/sites/www.seas.gwu.edu/files/downloads/ICICKM_2013_semin ar.pdf

51. Open KADS http://cordis.europa.eu/project/rcn/8773_en.html

52. Bramer M. (Ed) Artificial Intelligence - An International Perspective, Springer, 2009, http://www.springer.com/gp/book/9783642032257

53. Industry of the Future http://www.ambafrance-my.org/Towards-the-industrial-renewal-ofFrance-accelerate-deployment-of-the-Industry, 2015

54. $3^{\text {rd }}$ AI4KM, On IJCAI 2015, Buenos Aires.

55. Poniszewska-Maranda A., Kaczmarek D. : Selected Methods of Artificial Intelligence for Internet of Things Conception, Fedscis Proceedings, p. 1343-1348, DOI: 10.15439/2015F16, ACSIS, Vol. 5, 2015, Lodz. 